\title{
Why the Capability Approach is Justified
}

\section{SANDRINE BERGES}

ABSTRACT Sen and Nussbaum's capability approach has in the past twenty years become an increasingly popular and influential approach to issues in global justice. Its main tenet is that when assessing quality of life or asking what kind of policies will be more conducive to human development, we should look not to resources or preference satisfaction, but to what people are able to be and to do. This should then be measured against a more or less narrow conception of what any human being should be able to be and do, i.e. which functions are essentially human. To have a capability is to be able to function in that way. Thomas Pogge has recently argued that despite its many attractions, the capability approach did not present a sufficiently strong challenge to Rawlsian resourcism. In this paper, I address Pogge's criticisms of the capability approach, and I argue that from the point of view of Nussbaum's Aristotelian version of the approach, his objections are not successful.

\section{Introduction}

One of the selling points of the capability approach, as developed by Amartya Sen and Martha Nussbaum, is its relevance to questions of international distributive justice. Its supporters claim that it gives us a better answer to questions as to how we might measure quality of life and which policies will be more conducive to human development than welfarist or resourcist ${ }^{1}$ approaches can. ${ }^{2}$ Welfarist approaches give us unsatisfactory answers because peoples' statements as to whether they are satisfied with their lives are often not reliable. Preferences, Sen and Nussbaum argue, are adaptable, and it is unlikely that people who are badly off will be fully cognisant of what options could be made available to them. Resources approaches, even those that go beyond GNP and look at how much resources individuals have available to them, fail to take into account the fact that resources are not valuable in themselves, but only insofar as they enable us to function in certain ways. But as human beings differ in their abilities to transform resources into useful functioning, then a resourcist approach cannot tell us who is truly well or badly off. The resourcist approach isn't meant to tell us who is badly off in terms of either capabilities or welfare.

The capability approach, on the other hand, looks to what may be a more reliable indicator of social justice: what human beings are actually able to do and be. For example, in order to assess nutritional levels, the capability approach will not ask the subjects of the assessment whether they think they are well fed - a person who has never been adequately fed will probably not know what it is to have a full stomach. Nor will they ask how much food, or money to buy food is at their disposition - within a family the food available is not always equally distributed, children may get a larger portion than their mother, and sons a larger portion than daughters. Instead, the capability theorist will look at the subject's nutrition level, and factors which indicate whether that person 
is getting enough food in order, not to survive, but to live a normal, healthy human life. The capability approach thus presupposes a certain conception of what a good human life must be. In Sen's case, that conception is left deliberately vague, whereas Nussbaum endorses an Aristotelian/Marxian ${ }^{3}$ conception of human flourishing which she uses to back up a detailed list of human capabilities. ${ }^{4}$ This list in turn constitutes a threshold over which, she argues, it is nations' duty to bring every single individual.

If the capability approach defines itself even in part in contrast to other approaches, then for the capability approach to be justified, it has to be the case that it can really do something that the other approaches cannot do. Thomas Pogge, in a recent paper, has argued that 'neither Sen nor Nussbaum has so far shown that the capability approach can produce a public criterion of social justice that would be a viable competitor to the more prominent resourcist views'. ${ }^{5}$ He claims that Sen and Nussbaum overstate the difference between resourcist approaches and the capability approach, which according to him, amounts to nothing more than the question whether natural human diversity (i.e. mental or physical traits which lower people's ability to convert resources into valuable functioning, and which are not caused by past or present social injustice) should be compensated. Secondly, Pogge argues that the capability theorists are guilty of the straw man fallacy, that is, they compare the capability approach to a form of resourcism that is not the most plausible one available. Pogge concludes that the capability approach is not justified as a self-standing theory of social justice, even though it may be a useful appendage to resourcist theories.

In this paper, I want to argue that even if Pogge is right because the capability approach does not (as yet) offer a unified criterion for justice, it remains that the findings of the capabilities approach show up some fundamental weaknesses in the resourcist approach, and that it is not clear these weaknesses can be addressed from within the resourcist approach. I will object to Pogge's conclusions on two counts. First, I will disagree with Pogges' claim that resourcists can just as effectively accommodate human diversity as the capability approach does. I will show that the arguments he gives to that effect reach insufficiently strong conclusions, and that a resourcist approach simply would not be able to reach more satisfactory, stronger conclusions. Secondly, I will dispute his claim that the main source of disagreement between the capability and the resourcist approaches should be couched in terms of compensation for natural disadvantage. I will argue that the concept of compensation itself is not compatible with Nussbaum's version of the capability theory, and that there are good reasons to regard this concept as unhelpful in establishing social justice. In doing this I hope to bring out the scope of the differences between Nussbaum's Aristotelian/Marxian account, and Sen's more neutral account.

I concentrate on the contrast between capabilities and resources, and say nothing of preference satisfaction or welfare approaches. No doubt the capability theorists can be accused of attacking straw men there as well, in that they do not consider sophisticated competitors. I anticipate that preference satisfaction theorists will express their doubts on the justifiability of the capability approach, and when they do, I imagine the defenders of the capability approach will find a satisfactory reply.

\section{Accommodating Human Diversity}

The capability approach argument against Rawlsian resourcism may be summarised thus by saying that conversion of resources into valuable functioning differ from people 
to people. In Sen's words: 'People have disparate physical characteristics connected with disability, illness, age or gender, and these make their needs diverse' ${ }^{6}$ For example, a middle class English girl and a girl from Eastern Turkey both have the right to free education. ${ }^{7}$ In this sense, they have equal access to a crucial resource. But whereas the former will avail herself of that right more or less automatically (she may not even be aware that it is a right and only think of it in terms of duty), the latter probably will not avail herself of it at all; this because she is a girl in a part of the world where education for women is under-valued, because she lives somewhere where schools, teachers, and books are scarce, and because her family is poor and may need her to stay at home to help with housework, or bringing up younger children. ${ }^{8}$

There is a prima facie case for saying the resourcist is missing something important, if he or she fails to account for the difference between the experience of school girls in middle class Britain and Eastern Turkey. But Pogge explains that a good resourcist approach would in fact allow for the kinds of diversity presented in the above example, i.e. gender, age, and sufferings inflicted by present and past social injustices. The implication is that Sen is attacking a straw resourcist, but not a Rawlsian theorist at his or her best. ${ }^{9}$

As far a gender inequalities are concerned, Pogge takes the line developed by Susan Moller Okin: resources should be distributed fairly within the family, not just shared out between household heads who can then go on to give a larger share to the male members of the family. ${ }^{10}$ This is by now a well-known argument, and clearly, resourcist theories are better for it. However, it is unclear whether it is a sufficient solution to the problems raised by the capability theorists. The Eastern Turkish girl has an individual right to free education. There might even be some state money allocated to her personally so that she can buy books, or a school uniform. But will this make any difference to whether she attends school? It will not make a difference as to whether she feels it is her duty to stay at home and help her mother, or as to whether she thinks education will do her any good. It will not make a difference as to whether her parents authority is decisive regarding her being allowed to leave home everyday to attend school, and to wear a school uniform without covering her head in the traditional way (the wearing of headscarf is not allowed in Turkish schools).

One possible reply for the resourcist is to point out that once again, we are attacking a straw man. The good resourcist will not conceive of resources merely as material or financial handouts, but as good institutional structures. ${ }^{11}$ Thus the right kind of resources for a Eastern Turkish girl would take the form of decent schools somewhere that is easily accessible, and a reliable, cheap bus service to get them to that school; possibly also libraries so that they may consult the books they cannot afford to own. It would be surprising if the presence of such institutions were not to influence school attendance positively.

Certainly, studies show that many Turkish children who do not go to school do not go because there are no good schools available in their neighbourhood. ${ }^{12}$ However, the same studies show that those children who fail to go to school because the schools available just do not seem to be worth the trouble of travelling to them, are on the whole, boys. Especially in more traditional areas, girls do not seem to have the freedom to choose not to go to school. They stay at home, not because the schools available to them are not good enough, but because no school would be better than staying at home to help their mothers with household chores and be able to lead her life in a 
properly pious and modest manner. Even if the schools were better and more easily accessible, these young women would most probably be kept at home by their parents. So it seems that although better institutional structures would make a difference to school attendance for boys, it would fail to make much of a difference for girls - as what is keeping them at home is not merely the absence of schools, but their parents' and community's reluctance to send them outside the home. ${ }^{13}$

Pogge attempts to solve these difficulties by claiming that the criterion of fair distribution is not resources themselves, but access to resources. ${ }^{14}$ Thus a girl who has been given a grant for school books but whose father is keeping that grant from her does not have access to resources. It is unclear, however, how access to resources can be measured without looking beyond distribution of resources. The notion of access is either too weak - the girl has access in principle to education, in that she could in principle take the bus every day to go to school in the next town - but her parents won't let her; or too strong - to have access in practice to education means that we must check the individual situation of each school age child and see to it that they are able to avail themselves of their right. But this begins to look like a study of capabilities, as the question to be asked would be 'is the child able to go to school, and function as we think a child ought to function?' not, 'is the child getting what we regard as a fair amount of educational resources?'. Thus, in order to institute access to resources as an indicator of social justice, it seems we need to enter the capabilities discourse. Without doing so, the appeal to access to resources simply is not workable. Pogge mentions this worry in a footnote and adds that the same difficulties apply to the capability approach. ${ }^{15}$ However, he fails to mention that Rawls's main objection to the capability approach is that it is not workable. ${ }^{16}$ Given that this is so, Pogge had better not expose the resourcist to that same objection.

So far it seems that Pogge is not entirely successful in challenging the capability theorist's general claim that gender injustices are better dealt with by capabilities than resources. However, in order to reclaim for the resourcist the ability to deal with human diversity, Pogge also challenges two specific examples that Sen frequently uses to show that the capability approach is more satisfactory than a resourcist one: the pregnant woman, and the lactating woman. ${ }^{17}$ If he is successful in answering Sen's concerns from a resourcist point of view, then we might expect him to be successful in answering other similar cases, and eventually build an overall picture of how the resourcist might deal with gender inequalities.

Pregnant and lactating women, Sen argues, need more resources than other people. ${ }^{18}$ For one thing, they need to eat more in order to stay in good health while supporting a growing foetus or infant. So equal distribution of resources fails to provide justly for women who will have children at some point in their lives. The relevant question to ask is not: does this woman have a fair share of resources? But instead: is she able to live as healthy and productive a life as other, non-pregnant, or non-lactating human beings are - or should be?

Pogge argues that the appeal to capabilities is unnecessary, and therefore unwarranted, as the resourcist will not consider the pregnant and lactating woman as a single human being, but as one adult plus one infant. So the woman will get enough food after all. She will also get whatever health care she would get for herself and in addition, health care for her child. She will not, thus, be any worse off than the non-pregnant or lactating members of her community. 
This reply, unfortunately, falls short of a solution. Pregnant and lactating women's needs are not equivalent to the needs of an adult plus an infant. The effects of pregnancy and lactating are such that they may negatively affect a woman's ability to function well independently of the wellbeing of the infant. Pregnant women suffer from fatigue and may not be able to carry on working in and outside the home as before they were pregnant. Thus they may lose all or part of their income. This will not affect the infant they are carrying, in the short term, at least, but it will affect the carrying mothers' ability to provide for themselves. Women who have given birth can suffer from severe depression. It is arguable that this would not affect their baby's health or well being, as they may still be able to care for a baby. But it will seriously affect their own ability to recover their pre-pregnancy professional and emotional lives. Or again, employed pregnant and lactating women need support from their work place so that they can get adequate privacy and comfort when they need to rest or express milk. It is not clear whether this need belongs to them qua women or to their child qua foetus or infant. That is, in order to address this need fully, we have to look at the pregnant woman as a special case, not the amalgam of woman and child. It follows from these considerations that the resourcist's move of treating pregnant and lactating women as one adult plus one infant will probably not suffice to ensure that these women are treated fairly. This is because they do genuinely have different needs qua being pregnant and lactating, needs that affect their ability to function well. One suggestion is that the resourcist may characterize pregnancy and lactation as tied to normal human needs, in a way similar to age-specific needs. ${ }^{19}$ Thus, a pregnant or lactating woman should have access to more food in the same way that a growing child should have access to more fat and protein rich food. This position is attractive in that it normalizes pregnancy, highlighting the fact that it is a human condition, and not just merely something that sets women apart and disadvantages them.

However, it raises some very difficult questions. Should the resources be made available to all women in equal quantities within a certain age group? If they are, then it is very difficult to make any headway in helping women in third world countries, i.e. countries where women who are very poor tend to have more children and less help then women who are well-off. So for example, more resources will be needed to set up women's clinics in villages where women get sick and sometimes die from pregnancy, than to help a well-off woman who will prefer to pay for her own private care than go to a state hospital anyway. Women in villages will need special care due to their especially hard lives, their poor diets, their lack of health education. They will also need assistance when it comes to contraception, and even abortion. As it is, this kind of care is provided for (in so far as they are any provisions) by charities and NGOs. If state resources were to be divided equally amongst all women of child bearing age, then it is safe to say that those who are most in need of such resources would not get enough, and that those who are already welloff would prefer to rely on the resources they can buy for themselves with their own money.

So although the idea that pregnancy and lactation should be treated as a normal human need is attractive in countries where there are no large differences in wealth, and in which all women would in principle benefit from an equal share of states resources ${ }^{20}$ this will not work in developing countries where the needs of some women are so much greater than the needs of others.

In a further attempt to show that resourcism is able to deal with the difficulties which the capability approach claims that it alone can deal with, Pogge argues that inequality 
which is caused by past and present social injustices can and should be taken into account by a good resourcist theory. People who have in the past received insufficient resources because they were part of an unjust social order have a claim to compensation if the result of this past injustice means that they are less able to derive benefit from resources than others. This means that people who suffer from mental disability because their mothers were malnourished when they were pregnant can claim a larger portion of resources as part of a fair distribution. More generally, people who have been born or brought up in deprived backgrounds may claim compensation for the fact that they are now less able to derive benefit from education, or political rights than their fellow citizens, if the reason they were deprived was an unfair distribution of resources.

Here again, Pogge puts the resourcists in the way of Rawls's objection to the capability approach: it isn't workable. There are at least two reasons why it is not. First, to establish that someone is victim of past injustice in the form of unfair distribution of resources means that somebody must accept responsibility for that injustice. This point is most striking in the context of global justice. In order to decide on a fair treatment of people living in developing countries, we would first need to establish which responsibilities western governments should accept for the condition of the Third world, how much responsibility should be attributed to those countries' self-management, and how much to bad luck and climate.

Secondly, there is the problem of determining within a society, who qualifies for compensation. How do we determine which people deserve which kind of compensation? An address can tell us whether somebody lives in a poor area. But it cannot tell us which kind of house they live in (a nice house on the edges of that area, or a room in a crowded flat), whether they have lived there all their lives or whether they have just moved in (so that they may have received their education in a richer area), whether they are an established, well respected member of the community, or a scorned member. Similarly, race, country of origin, or even income bracket fails to yield the kind of information that would be needed in order to determine which people are owed compensation. For each of these categories, there is a strong risk that people who have not been subject to past injustices will be compensated, and that people who have, will be left out. For these reasons, a system of compensation for past injustices in the form of unfair distribution of resources is unworkable.

\section{Compensation and Aristotelian Values}

Pogge understands the dispute between the capability approach and resourcism thus: the capability approach claims that those with natural disadvantages should receive compensation, in the form of a greater allocation of resources. Resourcists disagree, but they do allow that some disadvantages should be compensated, for instance, those disadvantages due to pregnancy and lactation, and those due to past and present social injustices. I argued in the last section that a resourcist would in fact have some difficulties building a coherent account of how and why there should be compensations in those cases. In this section, I would like to argue that the way in which Pogge understands the difference between the capability approach and resourcism, in terms of compensation, is itself misguided. In order to do so I will emphasize an aspect of the 
capability approach which is specific to Nussbaum's writings, the Aristotelian take on human capabilities and flourishing, and show that, on her account at least, the capabilities approach is about something different from compensation.

In Women, Culture and Development, ${ }^{21}$ Nussbaum gives what she regards as the 'basic intuition' behind the capability approach: '. . . human capabilities exert a moral claim that they should be developed. Human beings are creatures such that, provided with the right educational and material support, they can become fully capable of the major human functions'. This intuition is derived from Aristotle's views on the relation of politics to human flourishing, that political arrangement must be based on a view of human functioning and capabilities, ${ }^{22}$ and Marx's take on this, that it is morally unacceptable that human beings should be reduced, by the conditions in which they have to live, to function in ways that are less than human, in other words, to live like animals. ${ }^{23}$

One consequence of regarding human functionings as morally significant is that it forces us to come to terms with the fact that resources are only ever means to achieving a fully human functioning, that they are only valuable insofar as they enable us toflourish. This implies the following criticism of resourcist approaches to human development:

'The basic intuitive idea used by the Aristotelian conception to argue against this [resourcism] is the idea that wealth, income, and possessions simply are not good in themselves. However much people may actually be obsessed with heaping them up (and Aristotle devotes much critical attention to this chrematistic tendency), what they have, really when they have them, is just a heap of stuff, a useful heap, but a heap nonetheless, a heap that is nothing at all unless it is put to use in the doings and beings of human lives'. ${ }^{24}$

Thus, resources are seen as goods only insofar as they contribute usefully to some aspect of human development. Resources that are not in practice effective in improving what a person can be or do are thereby worthless, even if in principle, they could be used for such improvement. This becomes clearer if we go back to our earlier example of Eastern Turkish schoolgirls. In their case, a resourcist might well decide that what they need is more money to buy books and school uniforms than children in richer areas of the country are allocated. No doubt they do. But in itself, this will not be sufficient to improve those girls school attendance significantly, as one of the main reason they do not attend school, is that their parents do not encourage them (or in some cases allow them) to do so. But by shifting the focus from what we would consider a fair distribution of resources per se (who gets how much of what) to what needs to be done in order to help everybody live a fully human live, we are able to offer more satisfactory solutions. By asking what those girls need in order to be in a position where they can benefit from their right to free education, we might decide that as well as sending books to the regions in which there is poor attendance by girls, we should initiate information programs, designed to alleviate some of the parents' fears, and encourage them and their daughters to value education. Most importantly, any action designed to improve their lot should focus on this: what can we do to insure that they are able to function fully.

In the light of the above, I would like to suggest that Pogge's take on the disagreement between the capability approach and resourcism does not apply to Nussbaum's version of the capability approach. Pogge couches the difference between the two 
approaches in terms of compensation: who will get extra resources as a result of which disadvantage. ${ }^{25}$ However, from the point of view of an Aristotelian capability theory, talk of compensations is part of the problem rather than of the solution. Being given more resources is not necessarily conducive to increased capabilities. A family who is given more money towards the education of its daughters may well choose to spend the money on dowry to insure that their daughters marry a rich man and never need to work outside the home. This will hardly increase those daughters' ability to function in a fully human way!

Compensation is, in many cases, simply a way of reconciling people with the fact that they are disadvantaged, not a way of making sure they are not. Of course, it need not be. People who for some reason or other are at a disadvantage capability wise, often do need more resources devoted to them than others. Building more schools, equipping them with books and writing material, developing information and education programs for parents as well as children cost money. But that money would be spent not with a view to compensating individuals who have suffered from the disadvantages imposed on them by their social position, but with a view to ensuring that all individuals are able to develop the capabilities that so far they have been unable to develop. Thus resources would be allocated by calculating, not how much each individual deserves as compensation, but how much is needed in order to bring a group of individuals above a certain threshold of capabilities.

\section{Conclusion}

Pogge does not condemn the capability approach. Instead, he maintains that it is very useful, both as a heuristic, in order to come up with the best possible list of goods to be distributed by the resourcist, and as a touchstone for existing resourcists, which would enable them to revise their criteria.

But has Pogge given us good reasons to think that the resourcist will do the jobs as well as the capability theorist, even with the latter's help? No he has not. First, the resourcist does not have a satisfactory way of dealing with the special requirements of pregnant and lactating women, or of people from deprived backgrounds suffering from the consequences of past and present injustices. Secondly, the claim that these people's hurts can be made better by compensation, is, we saw, misguided: compensation is not equivalent to assistance in developing capabilities, and therefore, it does not represent a just treatment of those who receive it.

Moreover, even if the resourcist approach could in practice do all that the capability approach can (which it can't), it remains that the capability approach is a more illuminating theory which offers compelling reasons why we should promote certain capabilities. The resourcist approach, by refusing to commit itself to a theory of the human good, deprives itself of the ability to put forward good, enduring reasons for the proposed list of resources to share (primary goods), and lays itself open to the objection that the consensus on what the primary goods are, is only the consensus of an intellectual, welloff minority.

Sandrine Berges, Department of Philosophy, Bilkent University, 06800 Bilkent, Ankara Turkey.berges@bilkent.edu.tr 


\section{Acknowledgements}

I would like to thank the following people for their helpful comments on earlier drafts and presentations of this paper: Thomas Pogge; Bill Wringe, Simon Wigley, and participants of the Bilkent philosophy seminar; Jerome Ballet and the members of the C3ED who participated in the 'Journee d'Ethique' at Bois le Roi in June 2004; and an anonymous referee.

\section{NOTES}

1 T. Pogge, 'Can the capability approach be justified', Philosophical Topics 30.2 (2002): 167-228, at page 176. I follow Pogge in using 'resourcist' and 'resourcism' to refer to Rawlsian views. Dworkin's conception of resources seems a lot closer to Sen's capabilities and therefore is not under discussion here. So by resources I mean social, not personal, or internal goods. See R. Dworkin, 'What is equality? Part 2: Equality of resources', Philosophy and Public Affairs 10 (1981): 283-345.

2 One might object that not all resourcists will be interested in how an index of resources can be used to measure wellbeing. For example, on Dworkin's resource egalitarian view, resources are regarded as a means of achieving liberty rather than a measure of wellbeing. However, as I have already noted, Dworkin's resources are arguably closer to Sen's capabilities (especially when Dworkin talks of 'internal resources'), than they are to Rawls' resources. See footnote 1 above and cf. Pogge op. cit. p. 176. I am grateful to Alan Carter for emphasizing this point.

3 I use Nussbaum's term 'Marxian' rather than the more usual 'Marxist', to refer to Karl Marx's philosophy in general and in particular, his conception of human nature, rather than his theorizing on economics.

4 For Nussbaum's list of capabilities see M. C. Nussbaum and J. Glover, (eds), Women, Culture and Development (Oxford: Clarendon Press, 1995), pp. 83-85.

5 Pogge op. cit. p. 167.

6 A. Sen, Development as Freedom (Oxford: Oxford University Press, 1999), p. 70.

7 In Rawlsian theory, rights count as a kind of primary goods, i.e. resources to be distributed fairly. See J. Rawls, The Law of the People, (Cambridge, MA: Harvard University Press, 1999), p. 13.

8 For a discussion of capabilities and school girls in Eastern Turkey, see A. Akkoyunlu-Wigley and S. Wigley, 'Basic Education and Capability Development in Turkey', in A-M. Nohl, (ed.) Education in Turkey (New York/Münster: Waxmann Publishing, forthcoming).

9 Pogge op. cit. p. 178.

10 Pogge op. cit. p. 180. See S. M. Okin, fustice, Gender and the Family (New York: Basic Books, 1989).

11 I owe this point to Thomas Pogge in informal discussion.

12 See the ILO report on child labour in Turkey 1999. http://www.ilo.org/public/english/standards/ipec/ simpoc/turkey/reports/turk99.pdf

13 It could be objected that for Rawlsians the family is an institutional structure, so that 'better institutional structures' would involve changes within the family. However, what seems to be holding these young women back is not just their families, but a combination of that together with religion and community. It could be that any one or even two of these elements taken together would not prevent a girl from attending school, but this particular combination does. In this case, it is hard to see how the solution could lie in the transformation of family structure.

14 Pogge op. cit. p. 177. See also p. 182.

15 Pogge op. cit. footnote 41, pp. 16-17.

16 See J. Rawls, The Law of Peoples (Cambridge, MA: Harvard University Press, 1999), p. 13.

17 A. Sen, Commodities and Capabilities, (New Delhi: Oxford University Press. 1999), p.16 and A. Sen, Inequality Re-examined, (Oxford, Clarendon Press, 1992) pp. 33 and 113.

18 Sen (1992) op. cit. p. 113.

19 Thomas Pogge made these comments on an earlier version of this paper.

20 For instance, it is probably the case that all women resident in the UK benefit from midwives and health visitors attributed to them by the NHS during pregnancy and the post birth period - although maybe not to the same degree.

21 Nussbaum and Glover op. cit. p. 88. 
22 See Aristotle, Politics 1323a14017. Nussbaum makes this point in 'Aristotelian social democracy', in B. Douglass, G. R. Mara and H. S. Richardson (eds) Liberalism and the Good (London: Routledge, 1990), p. 208, and defends it with reference to Aristotle's writings in 'Nature, function and capability: Aristotle on political distribution', Oxford Studies in Ancient Philosophy, (Oxford: Oxford University Press, 1988) Supplementary Volume, pp. 145-183.

23 M. C. Nussbaum, 'Capabilities and social justice' International Studies Review 4.2 (2002): 122-135, at pp. $129-130$

24 Nussbaum (1990) op. cit. p. 210.

25 The resourcist herself need not make use of the concept of compensation. Pogge's argument only supposes that this is what the capability approach theorist does. 